\title{
БИОИНДИКАЦИОННАЯ ОЦЕНКА ГОРОДСКИХ УСЛОВИЙ
}

\author{
М. А. Клевцова, А. А. Михеев \\ Воронежский государственный университет, Россия \\ Поступила в редакиию 2 апреля 2019 г.
}

\begin{abstract}
Аннотация: В статье приведены наиболее существенные результаты исследований, проведенные в пределах города Воронежа по оценке экологического состояния урбанизированной среды на основе изучения реакций двух видов-индикаторов: березы повислой (Betula pendula Roth.) и тополя итальянского (Populus italica (Du Roi) Moench). Основными индикационными показателями служили величина флуктуирующей асимметрии листовых пластинок, а также жизненное состояние древостоев. По степени ухудшения состояния зеленых насаждений функциональные зоны города Воронежа можно расположитьв следующий ряд: рекреационная - жилая - транспортная - промышленная.
\end{abstract}

Ключевые слова: биоиндикация, урбанизированная среда, флуктуирующая асимметрия, зеленые насаждения, древесные растения, жизненное состояние, береза повислая (Betula pendula Roth.), тополь итальянский (Populus italica (Du Roi) Moench).

\section{The bioindication assessment of urban conditions}

\section{A. Klevtsova, A. A. Mikheev}

Abstract: The article presents the results of assessing the ecological state of the urbanized environment by reactions of woody plants Betula pendula Roth. and Populus italica (Du Roi) Moench. The main indicative indicators were the magnitude of the fluctuating asymmetry of leaf blades, as well as the vital status of tree stands. Functional zones of Voronezh can be placed in the following row: recreational residential - transport - industrial.

Key words: bioindication, urbanized environment, fluctuating asymmetry, green plantings, trees, vitality, Betula pendula Roth., Populus italica (Du Roi) Moench.

Исследования последних десятилетий как отечественных [4, 5, 8-10], так и зарубежных ученых показали, что древесные растения являются неотъемлемой частью окружающей среды городов и поселков по всему миру $[13,18,19,23]$. В условиях слабо равновесного состояния биотический компонент урбоэкосистемы испытывает влияние антропогенных стрессоров, а, следовательно, не успевает адаптироваться к быстро меняющимся условиям среды. При этом ответная реакция биоты проявляется в анатомо-морфологических, физиологических, биохимических, биоритмических отклонениях. В ряде случаев именно фиксация подобного рода изменений биологических систем позволяет диагностировать состояние окружающей среды и спрогнозировать возможные последствия техногенного влияния.

(С) Клевцова М.А., Михеев А.А., 2019

Материал статьи доступен по лицензии Creative Commons "Attribution" 4.0
В качестве цели настоящих исследований была выбрана оценка экологического состояния зеленых насаждений на территории города Воронежа.

Основными задачами, которые позволили достигнуть вышеуказанной цели, были следующие.

1. Разработать сеть площадок постоянного наблюдения мониторинга зеленых насаждений; оценить жизненное состояние древостоев.

2. Провести экологическую оценку территории города Воронежа на основе определения диагностического параметра - флуктуирующей асимметрии билатеральных структур (листовых пластинок березы повислой (Betula pendula Roth.) и тополя итальянского (Populus italica (Du Roi) Moench)). Следует отметить, что согласно современным данным тополь пирамидальный - это синонимичное название тополя итальянского [7].

Исследование было организовано поэтапно. Подготовительный этап был посвящен поиску и анализу научных публикаций отечественных и за- 


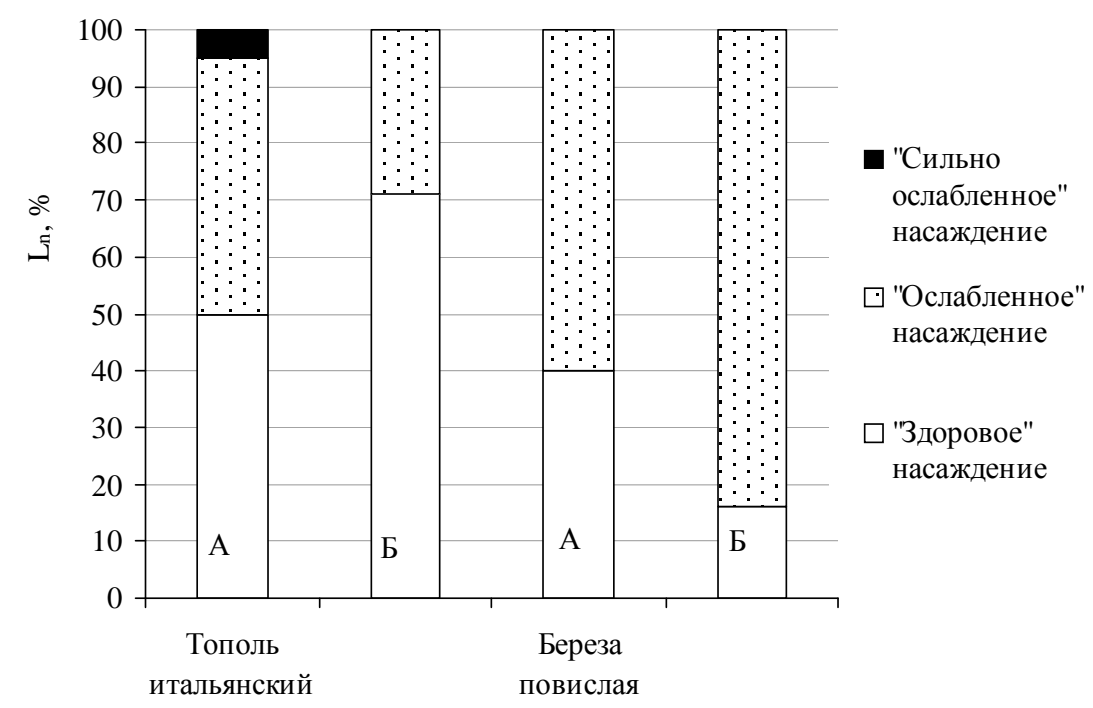

Рuc. 1. Распределение древостоев по показателю жизненного состояния (А - правый берег; Б - левый берег)

рубежных ученых по данной тематике, а также конкретизации целей и задач исследования. Следующий этап охватывал непосредственно эксперимент. Для изучения показателя флуктуирующей асимметрии и жизненного состояния древостоев проводились полевые и лабораторные исследования в течение летнего периода 2017-2018 годов. Для статистической обработки данных, а также их интерпретации мы использовали методы математической обработки информации на основе пакета анализа MS Excel и STATISTICA 12.6 (репрезентативность данных, асимметрия, эксцесс и др.). На завершающем этапе научной работы нами даны рекомендации по использованию результатов исследований в практической деятельности.

В нашем проекте акцентировалось внимание на вопросах изучения состояния зеленых насаждений по комплексу морфологических изменений у видов-индикаторов, представленных во всех функциональных зонах города.

Для проведения биоиндикационных исследований нами было заложено 75 пробных участков, где производился отбор растительного материала. Предварительно в данных пунктах мы провели рекогносцировочное обследование зеленых насаждений. Выбор ключевых участков осуществлялся таким образом, чтобы охватить равномерно территорию города Воронежа, все его функциональные зоны: селитебную (жилую), промышленную, транспортную, рекреационную. Контрольной точкой отбора послужили зеленые насаждения, произрастающие в пределах санатория им. Горького.

Изучение жизненного состояния проводилось согласно методике, предложенной В.А. Алексеевым [1]. Показатель флуктуирующей асимметрии определяли по методическим рекомендациям В. М. Захарова с коллегами [2, 3, 6].

Нами получены результаты интегральной оценки жизненного состояния по функциональным зонам за 2017-2018 годы, где $\mathrm{L}_{\mathrm{n}}$ - это относительное жизненное состояние древостоя, учитывающее распределение деревьев по категориям состояния.

Ухудшение жизненного состояния древостоев наблюдается в транспортной и промышленной зонах, что связано как с влиянием газообразных загрязняющих веществ, так и с экстремальными эдафическими условиями (переуплотнение, недостаток минеральных элементов, ухудшение водопроницаемости и аэрации почвы).

Насаждения тополя в жилой и рекреационной зонах относятся к категории «здоровых» $\left(\mathrm{L}_{\mathrm{n}}\right.$ 90,3 и $95,6 \%$ соответственно). В транспортной зоне преобладают ослабленные экземпляры $\left(\mathrm{L}_{\mathrm{n}} 72,5\right.$ \%), а в промышленной - древостои характеризуются как сильно ослабленные $\left(\mathrm{L}_{\mathrm{n}} 44,2 \%\right)$.

Обследованные насаждения березы повислой относятся к категории «поврежденных» $\left(\mathrm{L}_{\mathrm{n}}\right.$ колеблется в пределах от 63,7 до 69,1\%), а в промышленной зоне - «сильно ослабленных» $\left(\mathrm{L}_{\mathrm{n}} 40,4 \%\right)$. Исключение составляют насаждения рекреационной зоны ( $\mathrm{L}_{\mathrm{n}} 84,5 \%$ - категория здоровых насаждений).

На фоновом участке преобладают здоровые экземпляры (более $90 \%$ в насаждении). Тем не менее зафиксированы экземпляры, имеющие и признаки ослабления. Интегральный показатель жизненного состояния для насаждений тополя итальянского составляет 97,2\%, а для березы повислой - 96,8 \%. Эти данные согласуются с результатами исследований в 2014-2016 годах [10]. 


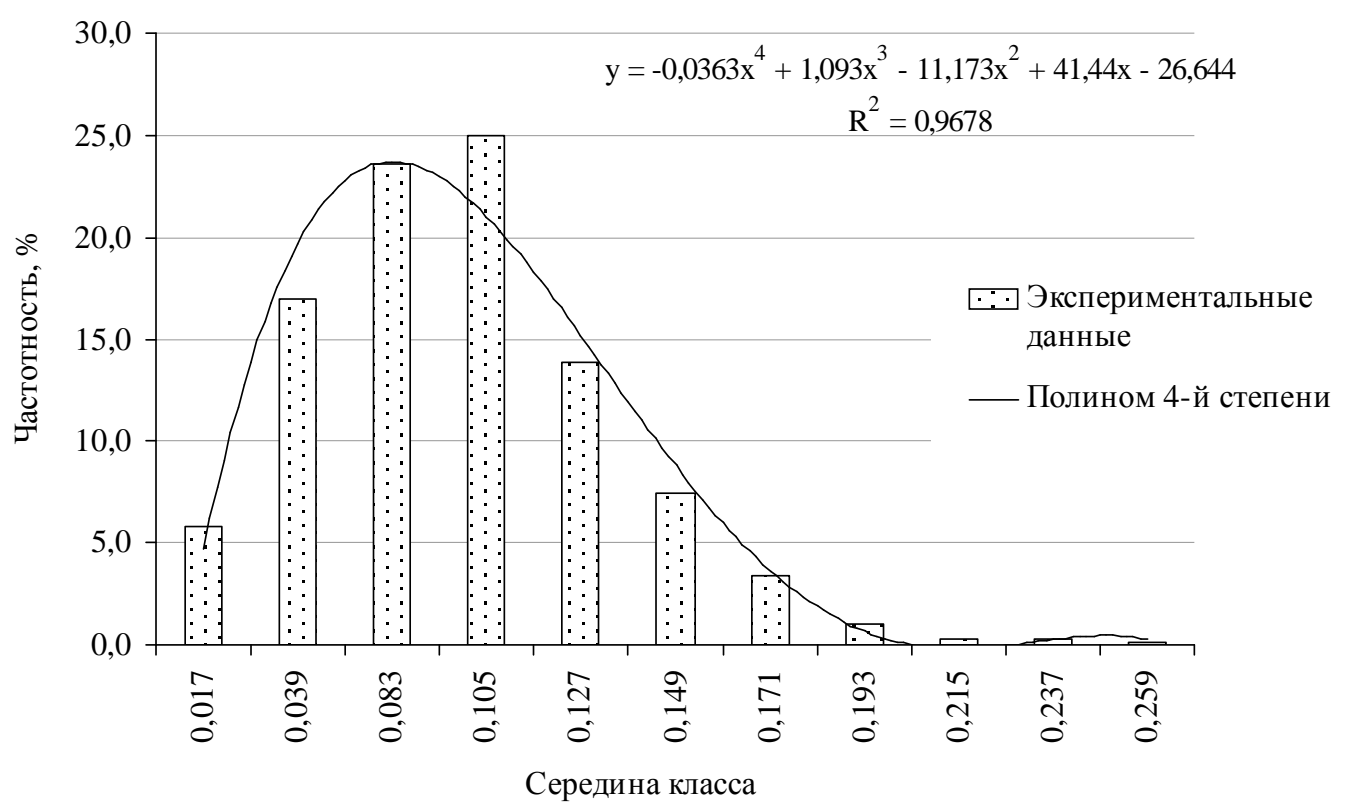

Puc. 2. Вариационный ряд величины флуктуирующей асимметрии листовых пластинок тополя итальянского

Экземпляры, произрастающие в промышленно-транспортное зоне, имеют механические повреждения: сухобочины, трещины в стволах, задиры коры, обломы ветвей. Например, значительная доля данного типа повреждений зафиксирована в точках № 8 (ул. Старых Большевиков, 47), № 26 (ул. Л. Рябцевой, 51), № 7 (Московский проспект, 36), № 29 (Ясный проезд, 13), № 38 (ул. Пирогова, 79), № 63 (ул. Урицкого, 47), № 65 (ул. 9 Января, 180). В качестве диагностического признака ухудшения жизненного состояния зеленых насаждений может выступать явление суховершинности. В настоящих исследованиях мы зафиксировали появление сухих ветвей у обоих видов. Так, если сквозистость кроны дерева достигает 50-60\%, то происходит своего рода «разрушение» кроны. Такие экземпляры уже относятся к категории «сильно ослабленных» [9].

В точках № 1 (ул. Ростовская, 44), № 24 (Московский пр-т - ул. Хользунова), № 34 (ул. Манежная - ул. С. Разина), № 44 (ул. Кривошеина, 11), № 68 (пр-т Патриотов, 3) отмечено значительное повреждение ассимилирующего аппарата насекомыми-вредителями, а также фитопатогенов.

Долгое время считалось, что усиление различий между правой и левой сторонами двустороннесимметричных структур происходят только под влиянием факторов окружающей среды, и этот аспект способствовал широкому использованию флуктуирующей асимметрии в качестве меры развития нестабильности в популяциях. До конца не изучено, какие конкретно гены управляют асимметрией как таковой. Но исследования показыва- ют, что уровни асимметрии у различных организмов находятся также под влиянием доминирования и особенно эпистатических взаимодействий между генами [17].

Распределение интегрального показателя жизненного состояния древостоев показано на рисунке 1.

Зеленые насаждения, произрастающие на левом берегу, испытывают большее влияние неблагоприятных факторов среды. Самая неудовлетворительная ситуация зафиксирована в точках № 15 (ул. Куйбышева - ул. Панфилова), № 8 (ул. Старых Большевиков, 47), № 10 (Ленинский проспект, 149). На указанных участках древостои Populus italica характеризуются как «отмирающие». Рассматриваемая территория по функциональной назначению относится к промышленно-транспортной зоне. Следовательно, здесь, как и в ряде районов города Воронежа, наблюдается явление синергического действия стационарных и передвижных источников техногенного загрязнения.

В целом по городу здоровые экземпляры видов-индикаторов зарегистрированы в $59 \%$ точек, если сравнивать с исследованиями 2014 года, то количество их возросло на $13 \%$. Тем не менее на каждой четвертой пробной площадке произрастают ослабленные экземпляры.

Таким образом, исследование жизненного состояния зеленых насаждений доказало, что данный биоиндикационный параметр может быть использован для оценки условий произрастания, a, следовательно, и для характеристики экологического благополучия экосистемы. 


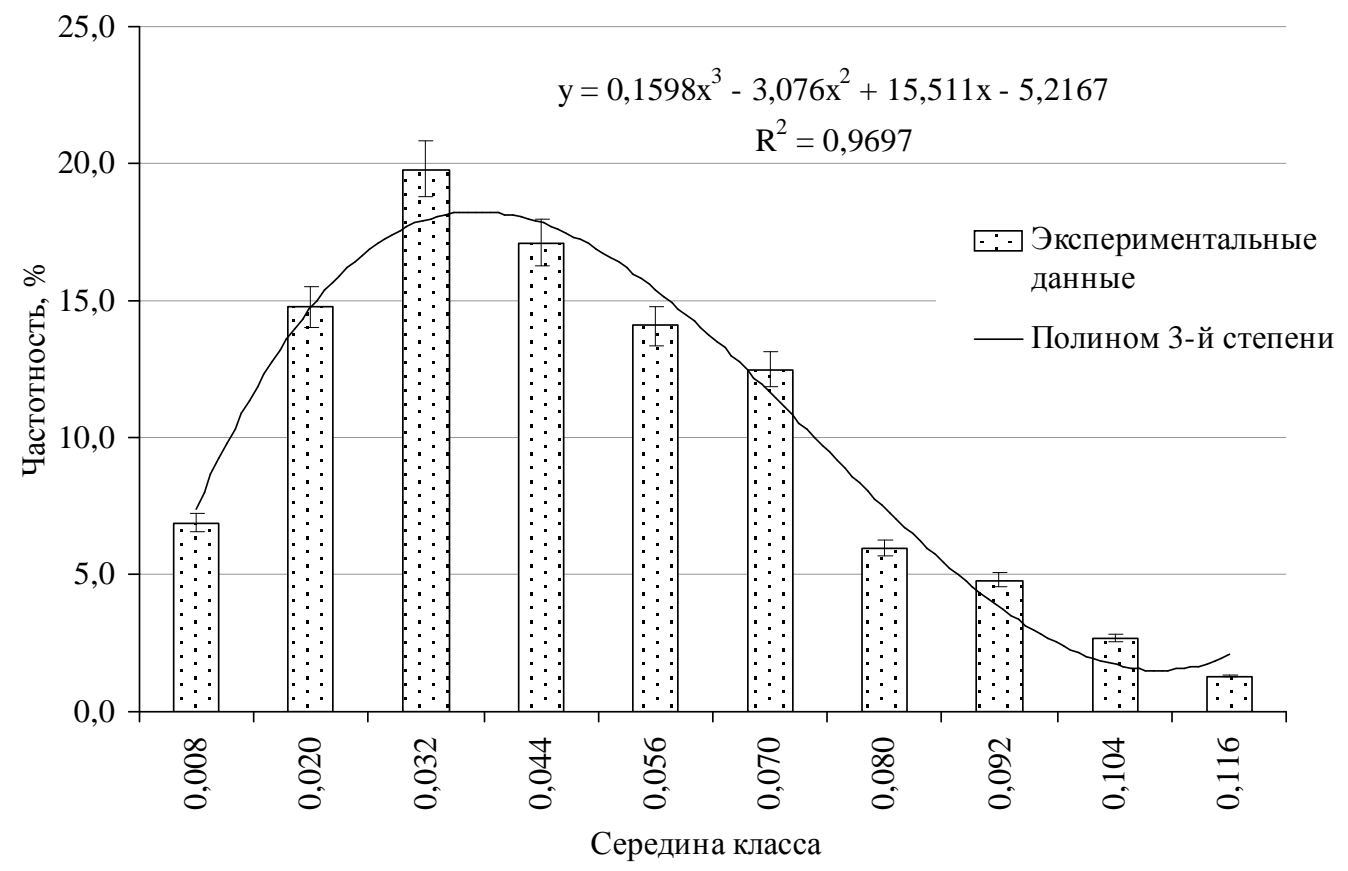

Puc. 3. Вариационный ряд величины флуктуирующей асимметрии листовых пластинок березы повислой

В нашем исследовании также реализовали сравнительный анализ изменчивости коэффициента флуктуирующей асимметрии листовых пластинок тополя итальянского и березы повислой. Отбор образцов для дальнейшего их изучения проводился в июне-июле 2018 года, когда ростовые процессы завершаются. Всего было изучено более 1500 экземпляров листьев.

Интегральный показатель флуктуирующей асимметрии листовых пластинок Populus italica варьирует в пределах от 0,018 до 0,260; березы повислой от 0,004 до 0,118 . В фоновой точке данный показатель для тополя составляет 0,054, а для березы - 0,006.

Распределение значений флуктуирующей асимметрии тополя итальянского можно описать уравнением полиномиальной кривой 4-й степени (рис. 2).

Для березы повислой показатель флуктуирующей асимметрии характеризуется уравнением полиномиальной кривой 3-й степени (рис. 3), выборка соответствует закону нормального распределения. Данная модель считается адекватной, т.к. критерий адекватности (аппроксимации) $R^{2}>0,95$. Кривая характеризуется положительной достоверной асимметрией $\left(A_{s}=0,448 \pm 0,076 ; t_{A s}=5,16\right)$ и эксцессом $\left(E=0,593 \pm 0,158 ; t_{E}=3,49\right)$.

По всем пяти признакам, которые используются для диагностики асимметричности вычисляли средний показатель асимметрии $M_{x}$ и ошибку сред- него $m_{x}$ для каждого листа. Затем рассчитывали усредненные показатели по функциональным зонам.

Экологические условия на рассматриваемой территории города Воронежа сильно варьируют. Минимальные значения интегрального коэффициента флуктуирующей асимметрии листовых пластинок видов-индикаторов отмечены, для образцов, отобранных в парке «Алые паруса», по ул. Шишкова, ул. Ломоносова, ул. Ипподромной, ул. Дарвина, ул. Нагорной. Наиболее высокие отклонения от нормы зафиксированы по ул. Ленинградской, ул. Димитрова, ул. Холмистой, ул. Пирогова, ул. Матросова, Московскому пр-ту, Рабочему прту. Как и в случае жизненного состояния, повышение асимметрии листовых пластинок наблюдается в точках, расположенных преимущественно в промышленно-транспортных зонах. Этот факт свидетельствует о снижении стабильности развития древесных растений.

Основываясь на полученных нами результатах биоиндикационных исследований, обследованные территории города Воронежа можно представить в следующем ряду в зависимости от степени ухудшения состояния урбанизированной среды: рекреационная зона - жилая зона - транспортная зона промышленная зона.

Флуктуирующая асимметрия описывает величину случайных различий в размере или форме между двумя сторонами у билатеральных струк- 
тур организмов. Данный показатель считается мерой нестабильности развития в результате изменений, происходящих в окружающей среды [14]. Поскольку обе стороны двусторонних морфологических признаков контролируются одним и тем же набор генов, степень асимметрии отражает неспособность особи поддерживать гомеостаз во время развития [20, 22]. Следовательно, повышенная флуктуирующая асимметрия может коррелировать с более медленным ростом, снижением плодовитости и выживанием по сравнению с более симметричными особями [12].

В отдельных исследованиях показано, что абиотические факторы, такие как загрязнение, высота над уровнем моря, климат и недостаток или избыток питательных веществ [15, 21, 24], а также такие биотические факторы как гибридизация, конкуренция, хищничество и паразитизм могут влиять на уровень асимметрии листовых пластинок растений $[11,16,17]$. При этом причину увеличения асимметричности у растений установить довольно сложно. Однако использование данного показателя в экологических исследованиях позволяет установить степень стрессового воздействия факторов среды.

Таким образом, в ходе проведения исследований мы показали правомерность использования методов биоиндикации при проведении экологического мониторинга зеленых насаждений на урбанизированных территориях.

Полученные результаты позволяют оценить уровень и характер флуктуирующей асимметрии, т.е. нестабильности развития растительных организмов под влиянием стрессовых факторов окружающей среды.

Исследование проведено при финансовой поддержке Русского географического общества, проект РГО-РФФИ № 17-05-41072.

\section{СПИСОК ЛИТЕРАТУРЫ}

1. Алексеев В. А. Диагностика жизненного состояния деревьев и древостоев / В. А. Алексеев // Лесоведение. - 1989. - № 4. - С. 51-57.

2. Захаров В. М. Асимметрия животных / В. М. Захаров. - Москва : Наука, 1987. - 261 с.

3. Захаров В. М. Здоровье среды : методика оценки / В. М. Захаров. - Москва : Центр экологической политики России, 2000. - 66 с.

4. Иванова Е. Ю. Оценка состояния атмосферного воздуха города Нововоронежа биологическими методами / Е. Ю. Иванова // Вестник Воронежского государственного университета. Сер. География. Геоэкология. - 2013 . - № 1. - С. 157-162.
5. Мелькумов Г. М. Флуктуирующая асимметрия листовых пластинок клена остролистного (Acer platanoides L.) как тест экологического состояния паркоценозов городской зоны / Г. М. Мелькумов, Д. Э. Волков // Вестник Воронежского государственного университета. Сер. География. Геоэкология. - 2014 . - № 3. C. 95-98.

6. Методические рекомендации по выполнению оценки качества среды по состоянию живых существ (оценка стабильности развития живых организмов по уровню асимметрии морфологических структур) / Центр экологической политики России. - Москва, 2003. - URL:http://www.ecopolicy.ru/upload/MetRecom.doc. (дата обращения 17.02.2019).

7. Плантариум : открытый онлайн атлас-определитель растений и лишайников России и сопредельных стран 2007-2019. - URL: http://www.plantarium.ru/ (дата обращения 10.01.2019).

8. Федорова А. И. Биоиндикация загрязнения городской среды / А. И. Федорова // Известия АН. Сер. географическая. - 2002. - № 1 . - С. 72-80.

9. Федорова А. И. Причины суховершинности и усыхания пирамидальных тополей в г. Воронеже / А. И. Федорова, Е. В. Шунелько, М. А. Михеева // Вестник Воронежского государственного университета. Сер. Химия. Биология. Фармация. - 2010. - № 1. С. 106-114.

10. Экологическая оценка состояния городской среды : сборник научных статей / [под общ. ред. С. А. Куролапа, О. В. Клепикова]. - Воронеж : Научная книга, 2016. - $151 \mathrm{c}$.

11. Contrasting herbivory patterns and leaf fluctuating asymmetry in Heliocarpus pallidus between different habitat types within a Mexican tropical dry forest / P. Cuevas-Reyes [et al.] // Journal of Tropical Ecology. - 2011. - Vol. 27. P. 383-391.

12. Diaz M. Herbivore effects on developmental instability and fecundity of holm oaks / M. Diaz, M. J. Pulido, A. M. Moller // Oecologia. -2004. - Vol. 139. - P. 224-234.

13. Escobedo F. J. Urban forests and pollution mitigation: Analyzing ecosystem services and disservices / F. J. Escobedo, T. Kroeger, J. E. Wagner // Environmental Pollution. - 2011. - Vol. 159. - P. 2078-2087.

14. Freeman D. C. Developmental instability as a means of assessing stress in plants: a case study using electromagnetic fields and soybeans / D. C. Freeman // International Journal of Plant Science. - 1999. - Vol. 160. - P. 157-166.

15. Kozlov M. V. Leaf fall in white birch (Betula pubescens) is independent of leaf asymmetry / M. V. Kozlov // Canadian Journal of Botany. - 2004. Vol. 82. - P. 910-913.

16. Leaf fluctuating asymmetry increases with hybridization and introgression between Quercus magnoliifolia and Q. resinosa (Fagaceae) through an altitudinal gradient in Mexico / A. L. Albarran-lara [et al.] // 
International Journal of Plant Science. - 2010. - Vol. 171. - P. 310322.

17. Leamy L. J. The genetics and evolution of fluctuating asymmetry / L. J. Leamy, C. P. Klingenberg // Annual Review of Ecology and Systematics. - 2005. Vol. 36. - P. 1-21.

18. Livesley S. J. The Urban Forest and Ecosystem Services: Impacts on Urban Water, Heat, and Pollution Cycles at the Tree, Street, and City Scale / S. J. Liveley, E. G. McPherson, C. Calfapietra // Journal of Environmental Quality. - 2016. - Vol. 45(1). - P. 119-124.

19. Modeling tree shade effect on urban ground surface temperature / M. Napoli [et al.] // Journal of Environmental Quality. - 2016. - Vol. 45. - P. 146-156.

20. Moller A. P. Morphological developmental stability in plants: patterns and causes / A. P. Moller, J. A. Shykoff // International Journal of Plant Science. - 1999. - Vol. 160. - P. 135-146.

21. Moller A. P. Elm, Ulmus glabra, leaf asymmetry and Dutch elm disease / A. P. Moller // Oikos. - 1999. Vol. 85. - P. 109-116.

22. Palmer A. R. Fluctuating asymmetry: measurement, analysis, patterns / A. R. Palmer, C. Strobeck // Annual Review of Ecology and Systematics. - 1986. - Vol. 17. P. 391-421.

23. Planning for cooler cities: A framework to prioritize green infrastructure to mitigate high temperatures in urban landscapes / B. A. Norton [et al.] // LandscapeandUrban Planning. - 2015. - Vol. 134. - P. 127-138.

24. The effect of fluctuating asymmetry and leaf nutrients on gall abundance and survivorship / J. C. Santos [et al.] // Basic and Applied Ecology. - 2013. - Vol. 14. P. 489-495.

\section{REFERENCES}

1. Alekseev V. A., Diagnostika zhiznennogo sostoyaniya derev'ev i drevostoev [Diagnosis of the vital state of trees and stands]. Lesovedenie, 1989, No. 4, pp. 51-57.

2. Zakharov V. M., Asimmetriya zhivotnykh [Asymmetry of animals]. Moscow, Nauka, 1987, 261 p.

3. Zakharov V. M., Zdorov'e sredy : metodika otsenki [Environmental health: assessment methodology]. Moscow, Tsentr ekologicheskoy politiki Rossii, 2000, 66 p.

4. Ivanova E. Yu. Otsenka sostoyaniya atmosfernogo vozdukha goroda Novovoronezha biologicheskimi metodami [Assessment of atmospheric air in the city of Novovoronezh by biological methods]. Vestnik Voronezhskogo gosudarstvennogo universiteta. Ser. Geografiya. Geoekologiya, 2013 , No. 1, pp. 157-162.

5. Mel'kumov G. M., Volkov D. E., Fluktuiruyushchaya asimmetriya listovykh plastinok klena ostrolistnogo (Acer platanoides L.) kak test ekologicheskogo sostoyaniya parkotsenozov gorodskoy zony [Fluctuating asymmetry of leaf blades of maple maple (Acer platanoides L.) as a test of the ecological state of urban parkocenoses]. Vestnik Voronezhskogo gosudarstvennogo universiteta. Ser. Geografiya. Geoekologiya, 2014, No. 3, pp. 95-98.
6. Metodicheskie rekomendatsii po vypolneniyu otsenki kachestva sredy po sostoyaniyu zhivykh sushchestv (otsenka stabil'nosti razvitiya zhivykh organizmov po urovnyu asimmetrii morfologicheskikh struktur) [Guidelines for assessing the quality of the environment according to the state of living things (assessment of the stability of the development of living organisms according to the level of asymmetry of morphological structures)]. Tsentr ekologicheskoy politiki Rossii. Moscow, 2003, Available at: http:// www.ecopolicy.ru/upload/MetRecom.doc. (accessed 17 February 2019).

7. Plantarium : otkrytyy onlayn atlas-opredelitel' rasteniy i lishaynikov Rossii i sopredel'nykh stran 2007-2019 [Plantarium: open online atlas identifier of plants and lichens in Russia and neighboring countries 2007-2019]. Available at: http://www.plantarium.ru/ (accessed 10 January 2019).

8. Fedorova A. I., Bioindikatsiya zagryazneniya gorodskoy sredy [Bioindication of urban pollution]. Izvestiya AN. Ser. geograficheskaya, 2002, No. 1, pp. 72-80.

9. Fedorova A. I., Shunel'ko E. V., Mikheeva M. A., Prichiny sukhovershinnosti i usykhaniya piramidal'nykh topoley v g. Voronezhe [Causes of dryness and drying out of pyramidal poplars in Voronezh]. Vestnik Voronezhskogo gosudarstvennogo universiteta. Ser. Khimiya. Biologiya. Farmatsiya, 2010, No. 1, pp. 106-114.

10. Kurolap S. A., Klepikov O. V., Ekologicheskaya otsenka sostoyaniya gorodskoy sredy: sbornik nauchnykh statey [Environmental assessment of the urban environment: A Collection of Scientific Articles]. Voronezh, Nauchnaya kniga, 2016, $151 \mathrm{p}$.

11. Cuevas-Reyes P. and etc., Contrasting herbivory patterns and leaf fluctuating asymmetry in Heliocarpus pallidus between different habitat types within a Mexican tropical dry forest, Journal of Tropical Ecology, 2011, Vol. 27, P. 383-391.

12. Diaz M., Pulido M. J., Moller A. M., Herbivore effects on developmental instability and fecundity of holm oaks, Oecologia, 2004, Vol. 139, P. 224-234.

13. Escobedo F. J., Kroeger T., Wagner J. E., Urban forests and pollution mitigation: Analyzing ecosystem services and disservices, Environmental Pollution, 2011, Vol. 159, P. 2078-2087.

14. Freeman D. C., Developmental instability as a means of assessing stress in plants: a case study using electromagnetic fields and soybeans, International Journal of Plant Science, 1999, Vol. 160, P. 157-166.

15. Kozlov M. V., Leaf fall in white birch (Betula pubescens) is independent of leaf asymmetry, Canadian Journal of Botany, 2004, Vol. 82, P. 910-913.

16. Albarran-lara A. L. and etc., Leaf fluctuating asymmetry increases with hybridization and introgression between Quercus magnoliifolia and Q. resinosa (Fagaceae) through an altitudinal gradient in Mexico, International Journal of Plant Science, 2010, Vol. 171, P. 310322. 
17. Leamy L. J., Klingenberg C. P., The genetics and evolution of fluctuating asymmetry, Annual Review of Ecology and Systematics, 2005, Vol. 36, P. 1-21.

18. Livesley S. J., McPherson E. G., Calfapietra C.,The Urban Forest and Ecosystem Services: Impacts on Urban Water, Heat, and Pollution Cycles at the Tree, Street, and City Scale, Journal of Environmental Quality, 2016, Vol. 45(1), P. 119-124.

19. Napoli M. and etc., Modeling tree shade effect on urban ground surface temperature, Journal of Environmental Quality, 2016, Vol. 45, P. 146-156.

20. Moller A. P., Shykoff J. A., Morphological developmental stability in plants: patterns and causes, International Journal of Plant Science, 1999, Vol. 160, P. 135-146.

\section{Клевцова Марина Александровна}

кандидат географических наук, доцент кафедры геоэкологии и мониторинга окружающей среды факультета географии, геоэкологии и туризма Воронежского государственного университета, г. Воронеж, т. (473) 266-56-54, E-mail: klevtsova@ geogr.vsu.ru

Михеев Алексей Александрович

аспирант кафедры природопользования факультета географии, геоэкологии и туризма Воронежского государственного университета, г. Воронеж, т. (473) 266-56-54, E-mail: alexey.mikheev.88@gmail.com
21. Moller A. P. Elm, Ulmus glabra, leaf asymmetry and Dutch elm disease, Oikos, 1999, Vol. 85, P. 109-116.

22. Palmer A. R., Strobeck C., Fluctuating asymmetry: measurement, analysis, patterns, Annual Review of Ecology and Systematics, 1986, Vol. 17, P. 391-421.

23. Norton B. A. and etc., Planning for cooler cities: A framework to prioritize green infrastructure to mitigate high temperatures in urban landscapes, Landscape and Urban Planning, 2015, Vol. 134, P. 127-138.

24. Santos J. C. and etc., The effect of fluctuating asymmetry and leaf nutrients on gall abundance and survivorship, Basic and Applied Ecology, 2013, Vol. 14, P. 489-495.

Klevtsova Marina Alexandrovna

Candidate of Geographical Sciences, Associate Professor of the Department of Geoecology and Environmental Monitoring, Faculty of Geography, Geoecology and Tourism, Voronezh State University, Voronezh, t. (473) 266-56-54, E-mail: klevtsova@geogr.vsu.ru

Mikheev Alexey Alexandrovich

Postgraduate student of the Department of Nature Management, Faculty of Geography, Geoecology and Tourism, Voronezh State University, Voronezh, t. (473) 266-56-54, E-mail: alexey.mikheev.88@gmail.com 